\title{
Influence of sex on early growth of pig conceptuses
}

\author{
G. Cassar ${ }^{1}$, W. A. King ${ }^{2}$ and G. J. King ${ }^{1 *}$ \\ ${ }^{\mathrm{I}}$ Animal and Poultry Science, and ${ }^{2}$ Biomedical Sciences, University of Guelph, Guelph, Ontario, Canada \\ N1G 2W1
}

\begin{abstract}
Nineteen gilts were used in an experiment to examine the relationship between rate of development and embryonic sex on day 10 of pregnancy. All gilts were mated to the same boar approximately $24 \mathrm{~h}$ after detection of second oestrus. They were individually housed and fed similar diets until slaughter on day 10 of gestation (day $0=$ day of insemination) for subsequent recovery of the conceptus. All conceptuses were photographed and their surface areas $\left(\mathrm{mm}^{2}\right)$ measured by tracing outlines on a digitized tablet interfaced with a computer program. Within each litter, individuals were categorized as small, medium or large by three equal divisions of the size range between the smallest and largest member. Conceptuses were individually cultured in Medium 199 with $1 \%$ colcemid and stained with $4 \%$ Giemsa. Metaphase spreads were located and sex was determined by presence or absence of the $Y$ chromosome in at least two spreads from each specimen. A total of 214 conceptuses were recovered but only $125(58 \%)$ were successfully karyotyped. The overall sex ratio was not significantly different from 1:1 (57 males and 68 females; $P>0.25$ ). Sex was determined in 51 of 88 small embryos, 22 of 44 medium embryos and 52 of 82 large embryos and males represented $9(17.6 \%), 10(45.5 \%)$ and $38(73 \%)$, respectively. Logistic analysis indicated significantly more females in the small and significantly more males in the large groups $(P<0.001)$. Results demonstrate that most male conceptuses grow faster than females before commencement of attachment to the uterine lining.
\end{abstract}

\section{Introduction}

Synchronized interactions between conceptuses and the tubular genitalia are essential throughout development from pig zygote to neonatal piglet. Mortality may occur at any stage of gestation but the most critical time is the first 10 days (Lambert et al, 1991). Developmental asynchrony, particularly during the period between hatching from the zona pellucida and commencement of attachment to the uterine lining, may contribute to mortality since signals from faster developing individuals could modify the uterine environment to produce conditions that might not be optimum for slower developers (Pope and First, 1985; Dziuk, 1987; Pope et al., 1990). Bazer et al. (1988) proposed that faster and more uniform conceptus development between days 8 and 14 accounts for higher embryonic survival rates in Chinese Meishan pigs, a breed noted for its prolificacy (Bazer et al., 1988). Other workers, while not disputing high prolificacy in the breed, contend that mechanisms other than uniformity of development contribute to the larger litter sizes (Ashworth et al., 1992; Wilmut et al., 1992).

Genetic sex influences the rate of early development in mice. At the blastocyst stage or on day 9, larger conceptuses were mostly males and smaller conceptuses mostly females (Tsunoda et al., 1985; Seller and Perkins-Cole, 1987). A similar sex-size relationship occurs in cattle conceptuses derived in vivo and

${ }^{*}$ Correspondence.

Received 8 October 1993. in vitro (Avery et al., 1989, 1991; Xu et al., 1992). These sex differences in development rates occur before the appearance of the gonads, so cannot be a consequence of gonadal hormone action, and may be evident as early as the first cleavage (Yadav et al., 1993; Zwingman et al., 1993). Since the immediate preattachment phase is a critical period for conceptus survival in pigs, conceptuses were karyotyped to determine possible effects of genetic sex on development to this stage.

\section{Materials and Methods}

Yorkshire gilts were housed in groups at the Arkell Swine Research Centre and oestrus was detected by exposure to a boar between 08:00-10:00 and 16:00-18:00 $\mathrm{h}$ each day. At second oestrus, 19 females were mated to the same boar approximately $24 \mathrm{~h}$ after observation of initial signs of standing oestrus. Animals were then housed individually and fed appropriate amounts ( $1.5 \mathrm{~kg}$ ) of a corn-soybean diet until slaughter 10 days later (day $0=$ day of mating or second day of oestrus). Reproductive tracts were obtained immediately after exsanguination and conceptuses recovered by flushing each uterine horn with $20 \mathrm{ml}$ PBS. All recovered conceptuses $(n=214)$, still maintained in the isotonic flushing fluid, were photographed within minutes of recovery through a stereomicroscope for subsequent measurement (see below). Conceptuses were then cultured individually in Medium 199 with $20 \%$ fetal calf serum and 1\% colcemid (all obtained from Gibco, $\mathrm{New}$ York) for $4 \mathrm{~h}$ at $37^{\circ} \mathrm{C}$ in an atmosphere of $5 \% \mathrm{CO}_{2}$ in 


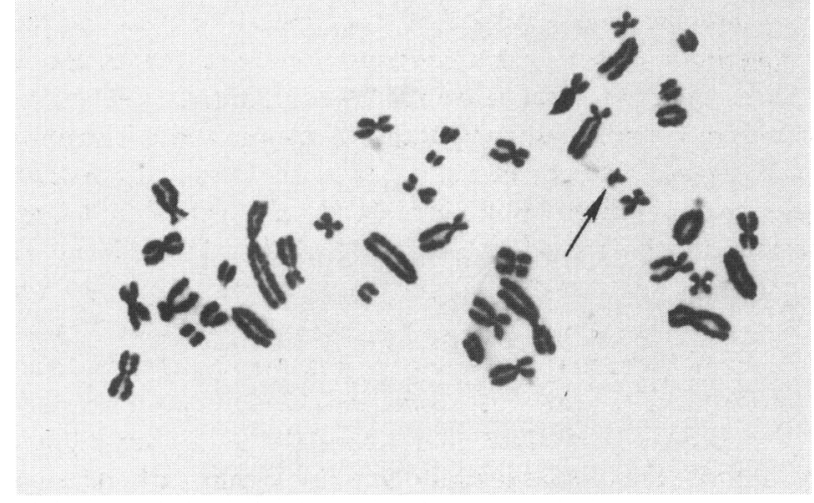

Fig. 1. Metaphase spread from a male pig conceptus on day 10 of gestation. Arrow indicates the $\mathrm{Y}$ chromosome.

humidified air and then prepared for karyotyping by the method described by Romagnano et al. (1985) with minor modifications. In brief, conceptuses were moved from the culture medium into $1 \%$ sodium citrate for $10-12 \mathrm{~min}$, fixed in a 3:1 (v:v) mixture of ethanol and acetic acid and transferred into $0.5 \mathrm{ml}$ of $50 \%$ acetic acid to dissociate cells. From the resulting suspension, five slides were prepared and stained with $4 \%$ Giemsa (Fisher Scientific, Pittsburgh, PA). Metaphase spreads were located and sexes determined by the presence or absence of the $Y$ chromosome in at least two spreads from each individual. Conceptuses whose sex could not be identified owing to lack of metaphase cells or readable metaphase spreads were classified as undetermined. After the cytogenetic study, individual images were measured by tracing outlines on a digitized tablet interfaced with a computer program designed to calculate surface areas $\left(\mathrm{mm}^{2}\right)$. Within each litter, individuals were classified and grouped as small, medium or large by three equal divisions of the size range between the smallest and largest litter members. Males, females and undetermined conceptuses were then matched to the size groups.

\section{Statistical procedure}

The overall sex ratio was tested by $\chi^{2}$ and logistic analysis used to compare proportions of male, female and undetermined conceptuses in the three size groups (SAS, 1988).

\section{Results}

Ovulations in the experimental animals averaged $14.05 \pm 2.1$ and a mean of $11.26 \pm 2.9$ normally developing conceptuses were recovered, giving a survival rate of $80 \%$. Uterine flushings from 19 gilts yielded a total of 214 conceptuses but only $125(58 \%)$ of these provided metaphase spreads suitable for successful karyotyping (Fig. 1). No metaphase spreads were obtained in any of the 12 specimens from one gilt; sex data therefore came from 18 litters. Of the 77 remaining conceptuses that could not be sexed, 56 had no metaphase spreads

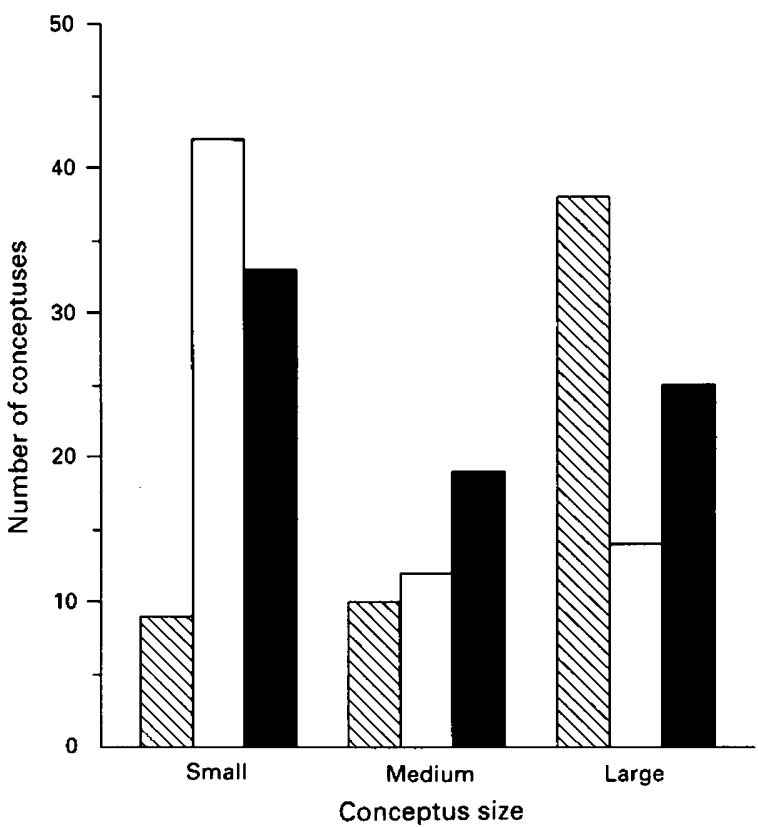

Fig. 2. Numbers of ( $\nabla$ ) male, $(\square)$ female and ( $\square$ ) sex-undetermined porcine conceptuses classified into small $(n=88)$, medium $(n=44)$ or large-sized ( $n=82$ ) groups within litter on day 10 of gestation.

and 21 had spreads that were not of sufficient quality to positively determine sex. One triploid individual was also found. The overall sex ratio of 68 females to 57 males was not significantly different from I:I $\left(\chi^{2}=0.97 ; P>0.25\right)$. The actual ratio of females:males for the three size groups within litters was $42: 9$ in small, $12: 10$ in medium and 14:38 in large groups (Fig. 2). Logistic analysis indicated that there were significantly more females $(P<0.001)$ among small conceptuses and more males in the large group. Sex ratio in the medium sized group was I:I. From the 18 litters that provided data, $42 \%$ (84) of all conceptuses were small, $20 \%$ (41) medium and 38\% (77) large. The distribution for 77 unsexed conceptuses was similar with $43 \%$ (33) small, $25 \%$ (19) medium and $32 \%$ (25) in the large sized groups $\left(\chi^{2}=1.08 ; P>0.1\right)$.

\section{Discussion}

Conceptuses recovered on day 10 after mating ranged in shape from small and large spheres to ovoid and tubular forms in keeping with previously reported variations (Hunter, 1974; Anderson, 1978; Pope and First, 1985; Pusateri et al., 1990). The range of sizes varied between litters but it was possible to partition each litter into small, medium and large groups. Karyotyping members in each of these three size divisions indicated that male pig conceptuses are generally larger than female conceptuses on day 10 after mating. This sex-size relationship is similar to that found in preimplantation mice (Tsunoda et al., 1985; Seller and Perkins-Cole, 1987; Valdivia et al., 1993) and cattle for blastocysts produced in vivo (Avery et al., 1989) and in vitro (Avery et al., 1991, 1992; Xu et al., 1992).

It has been proposed that at about day 10, the more developed conceptuses, through earlier synthesis of oestrogen, 
advance the uterine environment (Geisert et al., 1982) to allow preferential support for their survival and loss of smaller litter members (Morgan et al., 1987). Pope et al. (1990) and Xie et al. (1990) proposed that size variability at this stage of gestation results from the protracted period over which ovulation takes place. However, a recent study using transrectal ultrasonography to study ovulation in naturally ovulating sows indicated a relatively short range $(1.8 \mathrm{~h})$ for duration of ovulation and no relationship between ovulation time and conceptus diversity at approximately $100 \mathrm{~h}$ after the follicular rupture commenced (Soede et al., 1992). This relatively short duration of ovulation is similar to that reported for Meishan pigs (Martinat-Botte et al, 1989) and casts doubt on the suggestion that ovulations occurring over an extended period account for developmental diversity observed between day II and day 12 .

Various mechanisms might contribute towards the occurrence of phenotypic differences between the sexes before development of the gonads. Sex-determining region genes, Sry and $Z f y$ are transcribed at the two-cell stage in mouse zygotes, suggesting that sex determination starts before gonadal differentiation (Zwingman et al., 1993). Thornhill and Burgoyne (1993) contend that the paternally derived $X$ chromosome has a retarding effect on development in mice, while Tsunoda et al. (1985) and Burgoyne (1993) presented evidence that preimplantation sex differences in mice may be due to an accelerating effect of the $Y$ chromosome. Sex-related metabolic differences also appear early in gestation since total glucose metabolism in male bovine blastocysts collected directly from donor cattle 7 days after oestrus is greater than in females (Tiffin et al., 1991). Some or all of these mechanisms may be involved in pig conceptuses.

Lambert et al. (1991) proposed that most embryonic loss occurs within the first 10 days of gestation and, therefore, the sex ratio at the end of this period should be a reasonable representation of the ratio at birth. For the period January 1990 to December 1992, the secondary sex ratio of 14021 piglets from 1595 litters born in the research centre where the current experimental gilts originated was $1.07: 1$ (52\% males: $48 \%$ females). While sex ratio at fertilization is unknown, Pineda and Faulkner (1980) indicated that the secondary sex ratio in pigs approximates $1: 1$ with a range of $52.8-48.8 \%$ for males. In the present study, the ratio of sexed conceptuses was 0.84:1, 57 males $(46 \%)$ and 68 females $(54 \%)$. This is not significantly different from the expected 1:I ratio $(P>0.25)$, and with a larger sample size might be even closer to $1: I$. It is also within the range expected from previous results recorded in this herd.

In pigs, the theory of early gestational loss resulting from asynchrony of some conceptuses and the uterus implies that smaller or slower developing individuals die because the advancing uterine environment favours larger or more differentiated ones. The finding of sex-related developmental diversity indicates that females are smaller at the critical preattachment stage. If the above hypothesis is correct, more females would be lost and more males survive. It is generally expected that the sex ratio at birth is 1:1. If females are lost preferentially by virtue of their smaller size, then they must have been represented in greater numbers initially. There is, however, no evidence suggesting differential fertilization by $\mathrm{X}$ - or $\mathrm{Y}$-bearing spermatozoa. In the present study, there was $20 \%$ embryo loss by day 10 . While the cause of this loss is uncertain, greatest developmental diversity occurs 11-12 days after oestrus (Pusateri et al., 1990).

The numbers and sex distribution of conceptuses karyotyped indicated no bias towards identification of either males or females. Unsexed specimens $(n=77)$ were distributed among all size groups in a reasonably uniform manner and it is unlikely that there was any predominance of one sex among these. Even if the sex ratio was approximately equal in small and large specimens not successfully karyotyped, there would still be substantially more males among large and substantially more females among small conceptuses. Recovery rate was $80 \%$ on day 10, implying that the majority of losses had already taken place, so the sex ratio at that time should closely approximate to the sex ratio at birth (approximately 1:1). Karyotyping showed that the overall sex ratio was not significantly different from I:I, but there were significantly more males in the large and more females in the small groups $(P<0.001)$. Both sexes were equally represented in the medium-sized group. These results demonstrate that genetic sex influences the rate of development of pig conceptus before attachment commences and indicate that early survival-mortality is neither size nor sex-dependent.

The technical assistance of D. Sheppard and financial support of the Natural Science and Engineering Research Council of Canada and the Canadian Commonwealth Scholarship Plan is gratefully acknowledged.

\section{References}

Anderson LL (1978) Growth, protein, content and distribution of early pig embryos Anatomical Record 190 143-154

Ashworth CJ, Haley CS and Wilmut I (1992) Effect of Regumate on ovulation rate, embryo survival and conceptus growth in Meishan and Landrace $\times$ Large White gilts Theriogenology 37 433-443

Avery B, Bak A and Schmidt M (1989) Differentiated cleavage rates and sex determination in bovine embryos Theriogenology 32 139-147

Avery B, Madison V and Greve T (1991) Sex and development in bovine in vitro fertilized embryos Theriogenology 35 953-962

Avery B, Claus B, Jorgensen B, Madison V and Greve T (1992) Morphological development and sex of bovine in vitro fertilized embryos Molecular Reproduction and Development 32 265-270

Bazer FW, Martinat-Botte F and Terqui M (1988) Conceptus development in Large White and prolific Chinese Meishan pigs Journal of Reproduction and Fertility 84 37-42

Burgoyne PS (1993) A Y-chromosomal effect on blastocyst cell number in mice Development 117 341-345

Dziuk PJ (1987) Embryonic loss in the pig: an enigma. In Manipulating Pig Production, pp 28-39 Eds Australasian Pig Science Association Committee. Werribee, Australia

Geisert RD, Thatcher WW, Roberts RM and Bazer FW (1982) Establishment of pregnancy in the pig: III. Endometrial secretory response to estradiol valerate administered on day 11 of the estrous cycle Biology of Reproduction 27 957-965

Hunter RHF (1974) Chronological and cytological details of fertilization and early embryonic development in the domestic pig Sus scrofa Anatomical Record 178 169-186

Lambert E, Williams DH, Lynch PB, Hanrahan TJ, McGeady TA, Austin FH, Bowland MP and Roche JF (1991) The extent and timing of pre-natal loss in gitts Theriogenology 36 655-665

Martinat-Botte F, Bazer FW and Terqui M (1989) Embryonic survival mechanisms in Chinese Meishan (MS) and hyperprolific Large White (LWh) gilts. In Third International conference on Pig Reproduction Loughborough (Abstract 45) 
Morgan GL, Geisert RD, Zavy MT, Shawley RV and Fazleabas AT (1987) Development of pig blastocysts in a uterine environment advanced by exogenous oestrogen Journal of Reproduction and Fertility 80 133-141

Pineda MH and Faulkner LC (1980) The biology of sex. In Veterinary Endocrinology and Reproduction, pp 208-234 Ed. LE McDonald. Lea and Ferbiger, Philadelphia

Pope WF and First NL (1985) Factors affecting the survival of pig embryos Theriogenology 23 91-105

Pope WF, Xie S, Broermann DM and Nephew KP (1990) Causes and consequences of early embryonic diversity in pigs Joumal of Reproduction and Fertility Supplement 40 251-260

Pusateri AE, Rothschild MF, Warner CM and Ford SP (1990) Changes in morphology, cell number, cell size and cellular estrogen content of individual littermate pig conceptuses on days $9-13$ of gestation Journal of Animal Science 68 3727-3735

Romagnano A, King WA, Richer CL and Perron MA (1985) A technique for the preparation of chromosomes from early equine embryos Canadian Joumal of Genetics and Cytology 27.3 365-369

SAS (1988) SAS User's Guide: Statistics v. 6.03. Statistical Analysis System Institute Inc. Cary, NC

Seller MJ and Perkins-Cole KJ (1987) Sex difference in mouse embryonic development at neurolation Joumal of Reproduction and Fertility 79 159-161

Soede NM, Noordhuizen JPTM and Kemp B (1992) The duration of ovulation in pigs studied by transrectal ultrasonography, is not related to early embryonic diversity Theriogenology 38 653-666

Thomhill RA and Burgoyne PS (1993) A paternally imprinted X chromosome retards the development of the early mouse embryo Development 118 $171-174$
Tiffin GJ, Rieger D, Betteridge KJ, Yadav BR and King WA (1991) Glucose and glutamine metabolism in preattachment cattle embryos in relation to sex and stage of development Journal of Reproduction and Fertility 93 125-132

Tsunoda $Y$, Tokunga $T$ and Sugie $T$ (1985) Altered sex ratio of live young after transfer to fast and slow developing mouse embryos Gamete Research 12.3 301-304

Valdivia RPA, Kunieda T, Azuma S and Toyota L (1993) PCR sexing and developmental rate differences in preimplantation mouse embryos fertilized and cultured in vitro Molecular Reproduction and Development 35 121-126

Wilmut I, Ritchie WA, Haley CS, Ashworth CJ and Aitken RP (1992) A comparison of rate and uniformity of embryo development in Meishan and European White pigs Journal of Reproduction and Fertility 95 45-56

Xie S, Broermann DM, Nephew KP, Geisert RD and Pope WF (1990) Ovulation and early embryogenesis in swine Biology of Reproduction 43 236-240

Xu KP, Yadav BR, King WA and Betteridge KJ (1992) Sex related differences in developmental rates of bovine embryos produced and cultured in vitro Molecular Reproduction and Development 31 249-252

Yadav BR, King WA and Betteridge KJ (1993) Relationships between the completion of first cleavage and the chromosomal complement, sex and development rates of bovine embryos generated in vitro Molecular Reproduction and Development $36434-439$

Zwingman T, Erickson RP, Boyer T and Ao A (1993) Transcription of sexdetermining region genes Sry and Zfy in the mouse pre-implantation embryo Proceedings of the National Academy of Sciences USA 90 814-817 